\title{
Recovery and Utilization of Coking Chemical Products
}

\author{
Zijuan Peng \\ Chemical Engineering with Energy, North China Electric Power University, Baoding 073001, China \\ Email: 15932268721@163.com
}

Keywords: Coking chemicals; Recovery process; Optimization strategy; Analysis and exploration.

\begin{abstract}
This paper introduces the present status of coking industry in China and the types and uses of coking products, and lists the problems encountered in the recovery process and the recycling process. Putting forward the new technologies and the optimization of the process which can make the coking production process more scientific, reasonable and effective.
\end{abstract}

\section{The Present Status of Coking Industry}

China is a country with great coal resource and consumption. With the reduction of coal reserves, the processing and comprehensive utilization of coal has become the future direction of China's development. Coking of coal is an important aspect of comprehensive utilization of coal. It is also a branch of coal chemical engineering with relatively mature technology and high industrialization.

Coking chemical products plays an important role in the national economy and coking chemical industry also is an important sector of the national economy .It is one of the main parts of Integrated Steel Works. Meanwhile, it is the comprehensive utilization of coal industry.

In the past few years, the economic performance of coking industry showed the following general situation: The contradiction between supply and demand is more prominent, the product output and prices continued to decline and the operating efficiency declined significantly. In spite of the overall realization of China's coking industry structure optimization, energy saving, environmental protection, industrial upgrading, technical equipment modernization, and international capacity cooperation, there is still some room for adjustment, however, serious excess capacity and severe market competition have made some enterprises unable to withdraw from the market, which has become inevitable.

Coking chemicals used to be a by-product of coking plants. In recent years, with the increasing number of coking products and the importance of coking products in the development of national economy, coking chemical products have to get rid of the by-product position in the coking plant, like coke, has become the main products in the coking plant.

Therefore, in the existing scale of production, we need to fully separate the coking chemical products and optimize the recovery process of coking chemicals to get high yield and high quality products, at the same time, develop new production chain and increase the industrial production of by-products so as to improve the utilization ratio of raw materials, increase the efficiency of the whole industry and reduce the pressure of competition.

\section{Coking Products and Uses}

Coking industry is a comprehensive utilization industry of coal. It has a wide range of products and can reach more than 100 kinds, and has a wide range of uses. At present, the composition and application of the main products of coking industry in China are as follows.

\subsection{Coke}

Coke is the residual solid of coal after distillation at high temperature, The average yield is $72 \%$ $78 \%$.

Its main uses include blast furnace metallurgy, metallurgical coke, foundry coke, calcium carbide, ferrosilicon alloy, coke for production, gasification coke and other coke such as smelting of nonferrous metals and production of calcium, magnesium, phosphate. The coke powder with diameter 
less than $10 \mathrm{~mm}$ is mostly used in metallurgical enterprises smelting sinter, and a small amount of coke used for coking coal blending.

\subsection{Coke Oven Gas}

The main components of coke oven gas are hydrogen, methane, carbon oxides, ammonia and hydrocarbons.

The ammonia contained in the coke oven gas can be used to make ammonium sulfate, concentrated ammonia water or anhydrous ammonia. The main component of gas—-hydrogen, which can be used in the manufacture of synthetic ammonia and chemical fertilizers such as urea, harmonium nitrate, ammonium phosphate and ammonium carbonate are further made, which can be used directly in agricultural production.

The ethylene contained in the coke oven gas can be used as raw material for the production of ethanediol and dichloroethane.

By recycling of hydrogen cyanide and hydrogen sulfide from coke oven gas, we can not only get sulfur, sodium thiocyanate, thiosulfate, sodium ferrocyanide and other chemical products, but also control the pollution of air and water quality, strengthen environmental protection and reduce the corrosion of equipment, which is of great significance.

In the integrated steelworks, the coke oven gas, which has been recovered from chemical products, is a metallurgical fuel gas with high calorific value. It is an important fuel for the production of iron and steel. Coke oven gas can not only meet the needs of various heating furnace itself when produce steel, but also can be used as civilian fuel or be send to other chemical plants for the raw materials of chemical synthesis after deep desulfurization, dehydrogenation and purification.

\subsection{Crude Benzol And Crude Tar}

Crude benzol and crude tar are very complex semi-finished products in coking products. After refined processing, the main products are: carbon disulfide, benzene, toluene, xylene, mesitylene, coumarone, naphthalene, phenol, anthracene, carbazole, and so on. These products have a wide range of uses. They are precious to the plastics industry, synthetic fiber, synthetic rubber, pesticide, medicine, dyestuff, radiation resistant material, heat-resistant materials and national defense industry.

\section{Problems of Recycling}

The raw gas produced by coke oven carbonization chamber should be condensed, cooled and transported in the riser of the coke oven and the chemical product recovery workshop, and make the recovery of the chemical products and the purification of the gas are carried out. On the one hand, it is for the purpose of recovering useful chemical products, on the other hand, it is aimed at making the gas purification smoothly transported, stored and convenient for users to use.

In coke oven gas, except hydrogen, methane, ethylene, ethane and so on, the content of other components is small, but it is very harmful.

When the gas cools or flows through the equipment and pipeline with higher resistance, the crystals of naphthalene are precipitated, and they will deposit in the gas lines, causing blockage in some of the equipment; Tar can adversely affect the process of recovery of ammonia, benzene, etc. and can cause blockage due to metamorphism, hardening, or mixing with dust; hydrogen cyanide will generate molysite, ammonia will produce ammonium salt (ammonium carbonate, ammonium chloride, etc.);nitric oxide and hydrogen peroxide can be polymerized to a complex compound with butadiene, styrene, dicyclopentadiene, suspending in the form of colloidal particles, depositing, called gas glue, these substances can clog up the gas meter and are harmful to the transmission of gas.

Another serious problem is corrosion. Hydrogen sulfide, sulfide, hydrogen cyanide, ammonia in coal gas are water soluble acid and alkaline substances. When they are dissolved in water, they will cause corrosion in equipment and pipelines.

When gas is burned, sulfur dioxide and nitric oxide are produced, polluting the atmosphere and the environment.

For the above harmful impurities, not only will corrode the equipment and pollute the environment, but also affect gas transportation and recovery of ammonia, benzene and other chemical products. 
Therefore, according to the use of gas and the method of recovering chemical products, fferent processes should be adopted to remove them in different degrees.

\section{Recovery Process}

\subsection{Basic Production Section}

In integrated steelworks and a separate coking plant where produces furnace coke, the chemical products recycling workshop is often divided into the following production sections according to the gas flow path: Gas cooling and condensing section; Ammonia recovery section; Desulfurization section; Crude benzol recovery section; Ferro cyanide workshop.

The first three sections are the recoveries of the corresponding gas from the raw gas. Section of the Ferro cyanide task is recycling hydrogen cyanide (cyanide) from industrial wastewater.

The above recycling process is only a general classification. In fact, For different coking plants, the process system of chemical recovery is closely related to its production capacity and recovery of chemical products and the need for gas purification. Therefore, the section of the recycling workshop is not exactly the same.

The products produced in the recycling workshop are sent to the refining workshop for further processing to obtain more chemical products.

\subsection{New Production Process}

In 1970s, France and other countries developed the process system of recovering chemical products under total negative pressure.

In this system, the gas blower is arranged at the end of the whole system, and the gas is sent directly to the user.The advantage of this gas treatment system lies in: Before the blower, the gas system has been operated at a low temperature, and no final cooling is required before the ammonia is washed. The compressed heat generated in the blower remains to compensate for the heat loss during the gas transmission.

Since the end of 80 s, several sets of total negative pressure recovery systems have been introduced into China's coking plant. According to the methods of deamination and desulfurization, they can be divided into three different forms: Production of industrial sulfur by ammonia incineration; Indirect method for the production of ammonium sulfate and sulphuric acid; Anhydrous ammonia (or urea), and potassium Ferro cyanide and sulfuric acid.

The total negative pressure recovery system for the production of industrial sulfur by ammonia incineration is divided into primary cooling, electric tar precipitator and condensation treatment; sand filtration, washing; DE acidification, ammonia distillation; benzene distillation; aspirated gas engine, booster compressor; recovery control system for amino lysis; water supply. Since it was put into operation in 1990, the system has highlighted the obvious advantages compared with the traditional process recovery system in China.

\section{Optimization of Chemical Products Recovery Process}

At present, the analysis of a large number of practical work in coking plant shows that the corresponding recycling process of coking chemical products is not fully scientific and rational, and there are still many problems that need to be corrected urgently. The recovery process of coking chemical products lacks optimization, on the one hand it will reduce the technical and economic indexes, and on the other hand, it will seriously affect the surrounding natural environment. Therefore, how to optimize the recycling process of coking chemical products and put forward a scientific strategy to solve the problems is particularly important.

Usually, in the coking plant, the system and the production process will change with the production scale, the market, the funds for construction and so on, which will lead to certain differences in the determination of the production process. In general, in addition to the main production workshops, some plants also are equipped with crude benzol refining, coking plant coke oven gas to liquefied natural gas, coal tar deep processing and CDQ waste heat power generation and other production 
processes to extend the industrial chains. Therefore, it is a complex task to optimize the process of coking chemical product recovery, involving a lot of joint participation.

Differing from the usual recycling process, the order of recovery of chemical products through scientific and reasonable adjustment can achieve the corresponding ecological environmental effects and can fully ensure the economic benefits of enterprises. In the future research, we also need to analyze and do researches on the recovery process of coking chemical products, and thus make the coking production process more scientific, reasonable and effective, and optimize the production process and the various links, and ultimately, improve and enhance the quality of coking chemical products.

\section{References}

[1]. Yongrui Xu. Coking chemistry and coking products [J]. Jiangxi Metallurgy, 1997,(05):135-144.

[2]. Xiao Wang, Shunrong Hu. Optimization analysis of coking chemical recovery process [J]. Chemical Management, 2016, (33):74.

[3]. Aijuan Li. Optimization of the recycling process of coking chemical products [J].Petrochemical Technology, 2015 (04): 7. 